\title{
Monitoring Temperature and Heart Rate during Surgical Field Implantation of PTT-100 Satellite Transmitters in Greenland Sea Birds
}

\author{
Christian Sonne, ${ }^{1}$ Steen Andersen, ${ }^{2}$ Anders Mosbech,, ${ }^{1}$ Annette Flagstad, ${ }^{3}$ and Flemming \\ Merkel1,4 \\ ${ }^{1}$ Department of Bioscience, Faculty of Science and Technology, Aarhus University, Frederiksborgvej 399, P.O. Box 358, \\ 4000 Roskilde, Denmark \\ ${ }^{2}$ Hunters Science, Rådmandsgade 55, 2200 Copenhagen N, Denmark \\ ${ }^{3}$ Department of Small Animal Clinical Sciences, University of Copenhagen, Dyrlogevej 16, 1870 Frederiksberg, Denmark \\ ${ }^{4}$ Greenland Institute of Natural Resources, P.O. Box 570, 3900 Nuuk, Greenland
}

Correspondence should be addressed to Christian Sonne, csh@dmu.dk

Received 18 April 2011; Revised 23 June 2011; Accepted 24 June 2011

Academic Editor: Timm C. Harder

Copyright (c) 2011 Christian Sonne et al. This is an open access article distributed under the Creative Commons Attribution License, which permits unrestricted use, distribution, and reproduction in any medium, provided the original work is properly cited.

\begin{abstract}
Information on cloacae temperature (CT), heart rate (HR), Isoflurane use, and oxygen flow was collected during field implantation of Platform Terminal Transmitters (PTT-) 100 satellite transmitters in Greenland sea birds. Information was obtained from 14 intracoelomic and 5 subcutaneous implantations in thick-billed murres (Uria lomvia) and 9 intracoelomic implantations in common eiders (Somateria mollissima). CT decreased in the order subcutaneous murres $>$ intracoelomic eiders $>$ intracoelomic murres due to the explorative exposure to the surroundings and increased heat loss (murres smaller than eiders) and because the eider PTTs were preheated to $35^{\circ} \mathrm{C}$. During all implantations, heat loss was prevented using electric heat and rescue blankets. Regarding HR, the fluctuations were most pronounced during the intracoelomic murre implantations as a result of lower PTT temperature and lower body size leading to more pronounced digital manipulations and stimulation of the pelvic nerve plexus. Based on these results, we therefore suggest that HR and CT are carefully monitored in order to adjust anaesthesia and recommend the use of an electric heat blanket and preheating of PTTs to body temperature in order to prevent unnecessary heat loss causing physiological stress to the birds.
\end{abstract}

\section{Introduction}

In the Arctic, several sea bird species have been tracked by satellite telemetry, including thick-billed murres (Uria Lomvia), common eiders (Somateria mollissima), king eiders (Somateria spectabilis), and spectacled eiders (Somateria fischeri). Satellite telemetry is an effective tool in the mapping of migration routes and staging areas and has also been used to determine population levels of these different species [1-7]. This information has been utilized for planning and management of oil exploration activities, assessing the potential effects of climate change, and tracking the potential spread of emerging infectious diseases [2-7].

Employing satellite transmitters (PTTs) in wild birds requires either external attachment-by use of glue or har- nesses-or subcutaneous or intracoelomic surgical implantation during anaesthesia. Until now, only sparse field information has been available about the physiological responses of wild birds during such intracoelomic and subcutaneous surgical PTT implantation [8]. The purpose of the present paper is to describe the surgical and monitoring experiences from two field seasons of PTT implanting in Greenland murres and eiders. We present data from these two species using 3 different PTT types and 2 different implantation techniques (intracoelomic and subcutaneous). We show the impact on the birds' cloacae temperature and heart rate variation during surgery and how these variations may be prevented. This may be important practical information for scientists and veterinarians that plan to conduct surgical field PTT implantations in wild birds. 


\section{Materials and Methods}

2.1. Field Site and Surgical Implantation Procedure. We implanted PTT-100 in 19 murres and 9 eiders in the period 2006-2007 on license permission no. DPC-07-503 granted by the Greenland Self Government. The PTTs weighed either $29 \mathrm{~g}$ (murres) or $50 \mathrm{~g}$ (eiders) depending on the types of batteries supplied by the manufacturer (Microwave Telemetry, Columbia, Md, USA, http://www.microwavetelemetry.com). The murre colony was located at Ritenbenk $\left(51^{\circ} 16^{\prime} \mathrm{W}\right.$, $69^{\circ} 46^{\prime} \mathrm{N}$ ) in West Greenland where birds were caught at their nest site in July 2006. We implanted 14 intracoelomic and 5 subcutaneous PTTs of which the intracoelomic model was built as one unit while the subcutaneous model consisted of a battery and a transmitter connected by a wire. In East Greenland, June 2007, we implanted 9 intracoelomic transmitters in eiders taken at their nest site at Daneborg $\left(20^{\circ} 14^{\prime} \mathrm{W}\right.$, $\left.74^{\circ} 18^{\prime} \mathrm{N}\right)$. In the eiders, PTTs were gently preheated to $35^{\circ} \mathrm{C}$ prior to implantation. The ideal PPT weight is a maximum of $5 \%$ of the bird's body weight [9], and in neither murres (body weight: $800-1000 \mathrm{~g}$ ), or in common eiders (body weight: 1500-2000 g), this was exceeded (range: $2.5-3.5 \%$ ).

Presurgical preparations and surgical procedures followed Korschgen et al. $[10,11]$ with some modifications. Transmitters were disinfected in 70\% medical ethanol/isopropyl alcohol (12 h) prior to the implantation, and a sterile peritoneal Dacron cuff (DuPont Dacron cuff, DuPont, Wilmington, NC, USA) was attached at the antenna basis afterwards and secured with $5 \mathrm{~mm}$ sterile heat shrink plastic coating. Prior to anesthesia, a minimum of corneal lubricant (80\% Vaseline, $20 \%$ paraffin oil) was gently applied to prevent dryness. To reduce postrelease heat loss in the cold Arctic marine environment, feather removal was avoided at the abdominal and cervical incision sites (feathers were pushed aside by use of alcohol and subsequently taped). Ice was applied to the webbed skin of a few hyperventilating individuals. Birds were continuously anaesthetized through a closed-mask system using Isoflurane (Isovet, Merck \& Co, Schering-Plough Animal health, Whitehouse Station, NJ, USA) and medical oxygen (induction: $3 \%$ in $2000 \mathrm{~mL} \mathrm{O} \mathrm{O}_{2} \times \mathrm{min}^{-1}$; maintenance: $1.5-4.5 \%$ in $2000 \mathrm{~mL}$ $\mathrm{O}_{2} \times \min ^{-1}$ ) via a precision vaporizer and a modified Bains' coaxial system (Dameca Cyprane Limited Fluotec, Dameca a/s, Rødovre, Denmark). The antenna exit site was prepared as dorsocranially to the ischia bone as possible. Haemostatic forceps and a sharpened $4 \mathrm{~mm}$ urine metal catheter were used to perforate the subcutis, muscle layer, and peritoneum. The antenna was then pulled through the skin, and the cuff was secured tightly to the cutis and peritoneum with two single interrupted knots. Only the heat shrink coated antenna penetrated the skin. For calorimetric calculations on heat loss, we used the standard equation

$$
E=m \times c \times \Delta T \text {. }
$$

2.2. Surgical Monitoring. Murre surgeries were performed in a $12 \mathrm{~m}^{2}$ surgical theatre with temperature ranging $16.4^{\circ} \mathrm{C}-$ $24.2^{\circ} \mathrm{C}$, while eider surgeries were conducted in a boathouse with a temperature ranging $17.2^{\circ} \mathrm{C}-21.4^{\circ} \mathrm{C}$ (Table 1 ). The cloacae temperature $\left(\mathrm{CT} ;{ }^{\circ} \mathrm{C}\right)$ was continuously measured using an electronic thermometer with probe $(\mathrm{OBH}$ Nordica Type 4850/51, OBH Nordica Denmark a/s, Taastrup, Denmark). Heat loss was compensated by placing an electric heat blanket (OBH Nordica Type 4015, 50W, OBH Nordica Denmark A/S, DK-2630 Taastrup, Denmark; heat 1: low temperature at $30^{\circ} \mathrm{C}$ and heat 2 : high temperature at $50^{\circ} \mathrm{C}$ ) under the birds. In a few cases an alu rescue blanket (All Pro Rescue Blanket Co., Ltd., Qingdao, China) was placed over the birds. In addition, a heat gun (Black \& Decker, 2000W, Black \& Decker Headquarters, Towson, Md, USA) was used occasionally near-by the bird to warm up the surroundings. An electrocardiograph (ECG) (Schiller Cardiovit AT-4, Schiller AG, Baar, Switzerland) was employed to continuously monitor heart rate (HR; beats $\times \min ^{-1}$ ) which, together with extremity movements, corneal reflex, and respiratory frequency (monitored but not logged), constituted the base for adjustment of anaesthesia depth (Isoflurane \%). Isotonic Ringers acetate was used as vascular transmitter to obtain transduction of cardiac electric signal from skin to electrodes. Finally, the surgical site was inspected, and Enrofloxacin (Baytril, Bayer AG, Leverkusen, Germany) was administered to avoid infections (eiders: $12.5 \mathrm{mg}$ i.m.; murres: $8 \mathrm{mg}$ i.m.). Medical oxygen was administered until the bird had fully regained consciousness, and birds were held in a box fitted with absorbent pads until release 60-120 minutes after surgery. All data were logged manually, and a few of the murres were replaced at their nest sites but most were released on the top of the breeding cliffs in order not to disturb the colony. Eider ducks were released at their nesting ground. Based on PTT body core temperature, all released birds survived their first postsurgery month.

2.3. Statistics. SAS statistical software package (SAS 9.1 and enterprise guide V4.0, SAS Institute Inc., Cary, NC, USA) was used for the statistical analyses. A linear regression model incorporating time as explanatory and HR/CT as dependent variable was applied to investigate CT during the 3rd-16th minute and HR during the 7 th -15 th minute (Figure 1 ). The level of significance was set to $\alpha=0.05$.

\section{Results and Discussion}

3.1. Implantations. In general, CT decreased during all intracoelomic murre implantations which may partly be ascribed to the PTT temperature that was equal to ambient temperature $\left(16.4-24.2^{\circ} \mathrm{C}\right.$; Table 1$)$. The relationships between $\mathrm{CT}, \mathrm{HR}$, and Isoflurane concentration in murre number 41183 is shown in Figure 1. To maintain CT as accurate as possible, heat blanket was used stepwise (heat 1 after 6 minutes and heat 2 after 9 minutes). As the CT over a period of 12 minutes decreased significantly $(P<0.01)$ from 41.1 to $38.2^{\circ} \mathrm{C}$, the heat gun was used nearby the bird to warm up the surroundings just after the intracoelomic PTT in situ placement in the 16th minute (Figure 1). Furthermore, the heat blanket setting 2 was used from the 9th to 18th minute in order to prevent heat loss after PTT placement. From Figures 1 and 2, it is seen that, 
TABLE 1: Basic statistics (Mean $\pm \mathrm{SD}$, range) for continuously measured heart rate (HR), cloacae temperature (CT), Isoflurane concentration (Iso), oxygen flow $\left(\mathrm{mL} \times \mathrm{min}^{-1}\right)$, and ambient and PTT temperature $\left({ }^{\circ} \mathrm{C}\right)$ divided on implantation method and species.

\begin{tabular}{|c|c|c|c|c|}
\hline & \multicolumn{2}{|c|}{ Subcutaneous } & \multicolumn{2}{|c|}{ Intracoelomic } \\
\hline & Mean \pm SD $(n)$ & Min-Max & Mean $\pm \operatorname{SD}(n)$ & Min-Max \\
\hline \multicolumn{5}{|l|}{ Murres } \\
\hline HR (beats $\times \min ^{-1}$ ) & $213 \pm 46(5)$ & $134-288$ & $216 \pm 36(14)$ & $160-280$ \\
\hline $\mathrm{CT}\left({ }^{\circ} \mathrm{C}\right)$ & $41.3 \pm 0.7(5)$ & $40.4-42.8$ & $39.7 \pm 2.64(14)$ & $35.5-44.9$ \\
\hline Isoflurane (\%) & $2.75 \pm 0.48(5)$ & $2.0-3.5$ & $2.67 \pm 0.69(14)$ & $1.5-4.0$ \\
\hline $\mathrm{O}_{2}$ flow $\left(\mathrm{mL} \times \mathrm{min}^{-1}\right)$ & $2000 \pm 0.00(5)$ & 2000 & $2000 \pm 0.00(14)$ & 2000 \\
\hline Ambient (and PTT) temp. $\left({ }^{\circ} \mathrm{C}\right)$ & $21.83 \pm 2.05(5)$ & $19.7-23.8$ & $20.07 \pm 2.63(14)$ & $16.4-24.2$ \\
\hline \multicolumn{5}{|l|}{ Common eiders } \\
\hline HR (beats $\times \min ^{-1}$ ) & - & - & $212 \pm 42(9)$ & $145-280$ \\
\hline $\mathrm{CT}\left({ }^{\circ} \mathrm{C}\right)$ & - & - & $40.87 \pm 1.01(9)$ & $39.1-42.5$ \\
\hline Isoflurane (\%) & - & - & $2.4 \pm 0.71(9)$ & $1.5-3.5$ \\
\hline $\mathrm{O}_{2}$ flow $\left(\mathrm{mL} \times \mathrm{min}^{-1}\right)$ & - & - & $2000 \pm 0.00(9)$ & 2000 \\
\hline PTT temp. $\left({ }^{\circ} \mathrm{C}\right)$ & - & - & 35 & 35 \\
\hline Ambient temp. $\left({ }^{\circ} \mathrm{C}\right)$ & - & - & $19.91 \pm 1.42(9)$ & $17.2-21.4$ \\
\hline
\end{tabular}

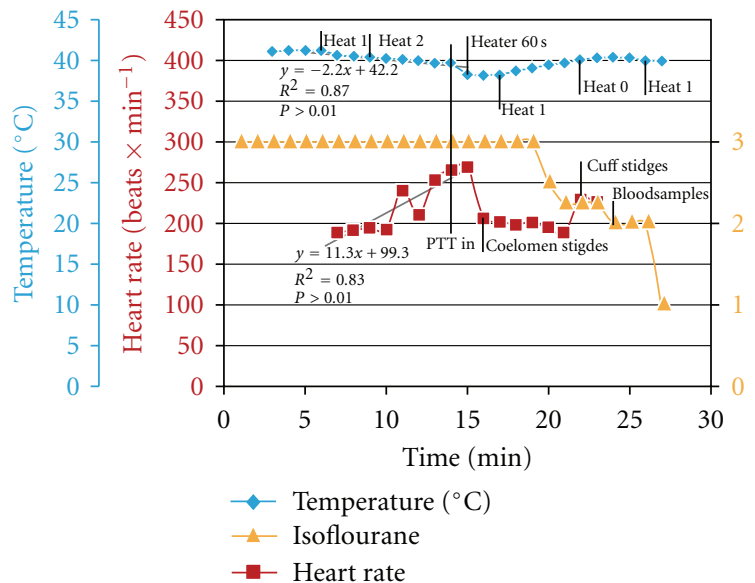

Figure 1: Example of murre cloacae temperature $\left({ }^{\circ} \mathrm{C}\right)$, heart rate (beats $\times \min ^{-1}$ ), and Isoflurane concentration $(\%)$ versus time (minutes) during intracoelomic PTT implantation (ID number 41183). Heat 1/Heat 2: heat blanket; heater: heat gun. Results from the linear regressions are added.

after 18 minutes, surgery CT increased to starting point and Isoflurane concentration was reduced from 3 to $2.5 \%$.

In murres, HR was relatively stable until intracoelomic digital manipulation at incision time after 10 minutes after which HR increased significantly $(P<0.01)$ by $40 \%$ (Figure 1). This increase occurred over a period of 5 minutes until the PTT was placed in the coelomic cavity at the 14th minute. The HR decreased to starting point during the 15th to 20th minute, after which the antenna cuff sutures were placed and CT increased. Although the coelomic cavity had been open for 5 minutes, the heat blanket seemed to counteract any significant heat loss. Some birds moved their legs simultaneously following perforation of the body wall with haemostatic forceps and metal urine catheter, probably due to a combination of body wall perforation, digital manipulation, and a stimulation of the pelvic nerve plexus.

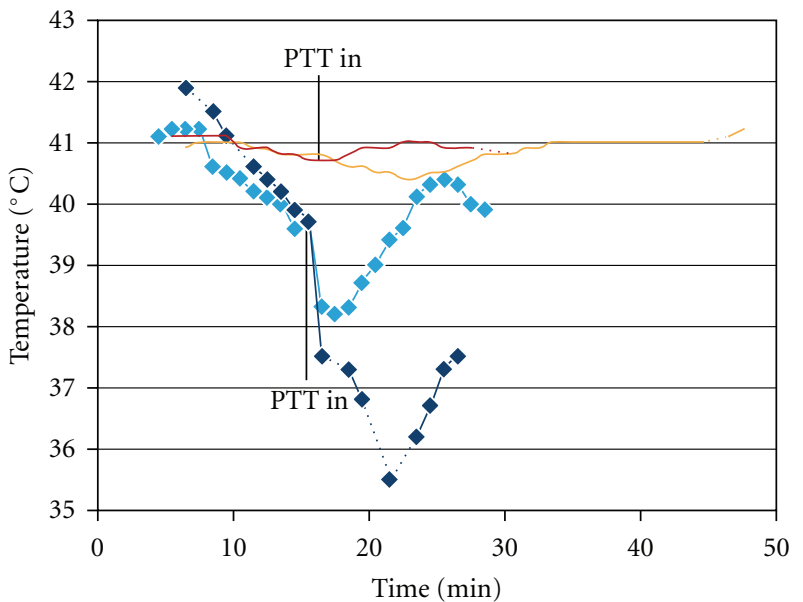

- Subcutaneous murre no. 41196 Subcutaneous murre no. 30059

$\neg$ Intracoelomic murre no. 41180

- Intracoelomic murre no. 41183

FIGURE 2: Cloacae temperature $\left({ }^{\circ} \mathrm{C}\right)$ versus time (minutes) during subcutaneous and intracoelomic PTT murre implantations. Note the difference in CT decrease between subcutaneous and intracoelomic implantations. Broken lines: data gaps.

Not surprisingly, the less explorative subcutaneous murre implantations did not influence $\mathrm{CT}$ as much as the coelomic procedure (Figure 2). Table 1 shows that the CT variation was only $1.4^{\circ} \mathrm{C}$ (Min-Max: $40.4-42.8^{\circ} \mathrm{C}$ ) in birds that were subcutaneous implanted compared to birds that were coelomic implanted and had a CT variation of up to $9.4^{\circ} \mathrm{C}$ (Min-Max: $35.5-44.9^{\circ} \mathrm{C}$ ).

According to Figures 1 and 3, a lower CT variation was recorded in the eiders when compared to the intracoelomic murre implantations probably due to larger body size (lower heat loss) and the use of preheated PTTs. Also HR seemed more stable during the intracoelomic eider implantations 


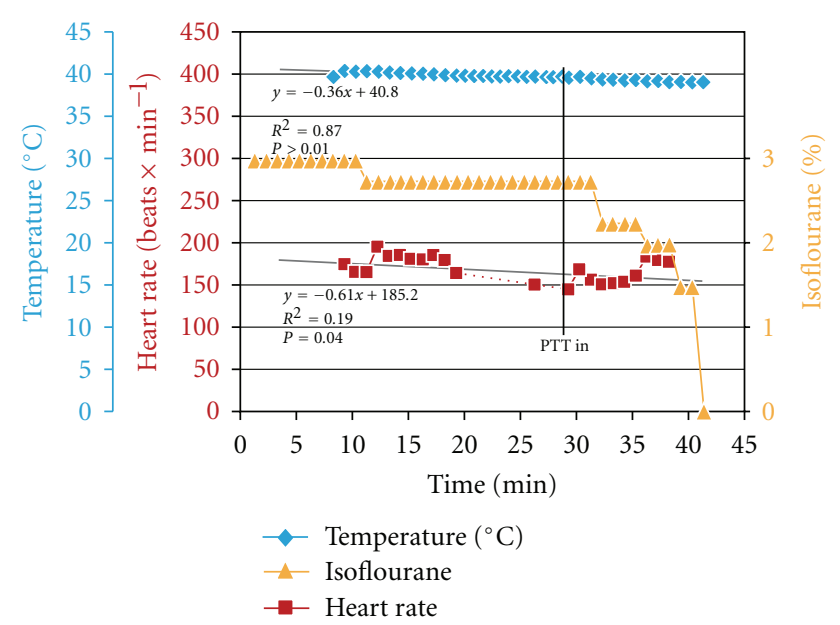

Figure 3: Example of eider cloacae temperature $\left({ }^{\circ} \mathrm{C}\right)$ compared to heart rate (beats $\times \mathrm{min}^{-1}$ ) and Isoflurane concentration (\%) versus time (min) during intracoelomic PTT implantation (ID no. 8). In this case, the PTT was preheated to $35\left({ }^{\circ} \mathrm{C}\right)$. Broken lines: data gaps. Results from the linear regressions are added.

either due to PTTs being preheated or due to species specific differences such as body size allowing more gently digital manipulations and thereby stimulation of the pelvic nerve plexus. No abnormalities in locomotion were seen at any bird release.

3.2. Interpretations. According to Figures 1 and 2, 75\% of the CT loss occurred 1-15 minutes prior to PTT in situ placement. This may be due to the effect from at least three factors that cannot be separated when using CT monitoring. First, birds may reduce CT due to presurgical preparation and/or due to the initial explorative exposure of the coelomic cavity. Also, the implantation of the relatively cold PTT and the digital manipulation of internal organs could reduce CT [12]. Secondly, the CT decrease following PTT placement may be influenced by the location of the relatively cold PTT close to the temperature sensor in the bird's cloacae. Thirdly, there is an anaesthetic depression of the oblongated medulla causing a malfunction of the temperature regulating centre [12].

Regarding PTT temperature and heat loss, the exact calorimetric value of the PTT could not be determined, and we therefore estimated it to equal the average of copper $(0.385 \mathrm{~J} / \mathrm{g})$, steel $(0.5 \mathrm{~J} / \mathrm{g})$, and plastic $(1.12 \mathrm{~J} / \mathrm{g})$ which is $0.668 \mathrm{~J} / \mathrm{g}$. The maximal estimated caloric cost of warming the $29 \mathrm{~g}$ and $50 \mathrm{~g}$ PTT from ambient temperature of $16.4^{\circ} \mathrm{C}$ to a CT of $41^{\circ} \mathrm{C}$ was $407 \mathrm{~J}$ and $701 \mathrm{~J}$, respectively, which is a negligible amount of energy (equal to $0.03 \mathrm{~g}$ of the prey species sand lance; Ammodytes dubius) [13]. However, any temperature change as well as stress induced by handling and surgery require increased foraging, resting, and preening by the bird in order to increase immune competence, maintain homeostasis, and counteract altered dive performance [1421]. The potential adverse effects from decreasing CT and oscillating HR should be avoided as they may prolong recovery time and subsequently reduce reproductive success and survival of the bird [14-16].
During intracoelomic surgery, HR increased, while CT decreased, which is in accordance with other experiences of anaesthetized bird species [8,17-21]. Anaesthetic depth is likely to be explanatory factors for HR increase and should therefore be adjusted in order to prevent or reduce HR variations. During PTT implantations in common eiders, the temperature monitored probably reflected true CT due to the larger physical separation of temperature probe and PTT within the coelomic cavity of this species. A preheated PTT and a larger separation of temperature probe and PTT were the only significant difference between the operation procedures of the two species. Not surprisingly, the decrease in CT was smallest during the subcutaneous implantations.

\section{Conclusions}

The decrease in cloacae temperature was most pronounced in intracoelomic implanted murres probably due to the explorative exposure to the surroundings and increased heat loss due to its smaller size and because murre PTTs were not preheated. Regarding heart rate, the fluctuations were also most pronounced during the intracoelomic murre implantations as a result of lower PTT temperature and lower body size leading to more pronounced digital manipulations and stimulation of the pelvic nerve plexus. It is therefore recommended to use electric heat blanket and preheated PTTs in order to prevent unnecessary heat loss causing physiological stress to the birds.

\section{Conflict of Interests}

No conflict of interests was reported and the submitted paper is not under consideration elsewhere.

\section{Acknowledgments}

Bureau of Minerals and Petroleum in Nuuk is acknowledged for financial support. Allan Juhl Kristensen and Rune K. Ritz are acknowledged for catching murres on their nest sites. Daniel M. Mulcahy, Thea $\varnothing$. Bechshøft. and Thomas Eriksen are acknowledged for comments on the paper.

\section{References}

[1] F. Huettmann and A. W. Diamond, "Seabird migration in the Canadian northwest Atlantic Ocean: molting locations and movement patterns of immature birds," Canadian Journal of Zoology, vol. 78, no. 4, pp. 624-647, 2000.

[2] F. R. Merkel, A. Mosbech, C. Sonne, A. Flagstad, K. Falk, and S. E. Jamieson, "Local movements, home ranges and body condition of Common Eiders (Somateria mollissima) wintering in Greenland," Ardea, vol. 94, no. 3, pp. 639-650, 2007.

[3] A. Mosbech, R. A. Danø, F. R. Merkel, C. Sonne, and H. G. Gilchrist, "Use of satellite telemetry to locate key habitats for King Eiders (Somateria spectabilis) in western Greenland," in Waterbirds Around the World: A Global Overview of the Conservation, Management and Research of the World's Waterbird Flyways, G. C. Boere, C. A. Galbraith, and D. A. Stroud, Eds., 
pp. 769-776, Edinburgh Stationery Office, Edinburgh, UK, 2007.

[4] A. Mosbech, H. G. Gilchrist, F. R. Merkel, C. Sonne, A. Flagstad, and H. Nygaard, "Comparing spring and autumn migration of Arctic Common Eider based on satellite telemetry," Ardea, vol. 94, pp. 651-667, 2007.

[5] M. R. Petersen and D. C. Douglas, "Use of implanted satellite transmitters to locate spectacled eiders at-sea," The Condor, vol. 97, no. 1, pp. 276-278, 1995.

[6] M. R. Petersen and D. C. Douglas, "Winter ecology of spectacled eiders: environmental characteristics and population change," The Condor, vol. 106, no. 1, pp. 79-94, 2004.

[7] M. R. Petersen, W. W. Larned, and D. C. Douglas, "Atsea distribution of Spectacled Eiders: a 120-year-old mystery resolved," Auk, vol. 116, no. 4, pp. 1009-1020, 1999.

[8] D. M. Mulcahy and D. Esler, "Surgical and immediate post release mortality of harlequin ducks implanted with abdominal radio transmitters with percutaneous antennae," Journal of Zoo and Wildlife Medicine, vol. 30, no. 3, pp. 397401, 1999.

[9] D. W. MacDonald and C. J. Amlaner Jr., "A practical guide to radio tracking," in A Handbook on Biotelemetry and Radio Tracking, C. J. Amlaner Jr. and D. W. MacDonald, Eds., pp. 143-159, Pergamon Press, Oxford, UK, 1980.

[10] C. E. Korschgen, K. P. Kenow, A. Gendron-Fitzpatrick, W. L. Green, and F. J. Dein, "Implanting intra-abdominal radiotransmitters with external whip antennas in ducks," Journal of Wildlife Management, vol. 60, no. 1, pp. 132-137, 1996.

[11] C. E. Korschgen, K. P. Kenow, W. L. Green, M. D. Samuel, and L. Sileo, "Technique for implanting radio transmitters subcutaneously in day-old ducklings," Journal of Field Ornithology, vol. 67, no. 3, pp. 392-397, 1996.

[12] A. J. M. Davis and B. Bissonnette, "Thermal regulation and mild intraoperative hypothermia," Current Opinion in Anaesthesiology, vol. 12, no. 3, pp. 303-309, 1999.

[13] M. D. Robards, J. A. Anthony, G. A. Rose, and J. F. Piatt, "Changes in proximate composition and somatic energy content for Pacific sand lance (Ammodytes hexapterus) from Kachemak Bay, Alaska relative to maturity and season," Journal of Experimental Marine Biology and Ecology, vol. 242, no. 2, pp. 245-258, 1999.

[14] P. L. F. Fast, M. Fast, A. Mosbech, C. Sonne, H. G. Gilchrist, and S. Descamps, "Effects of implanted satellite transmitter on behavior and survival of female common eiders," Journal of Wildlife Management. In press.

[15] J. W. Hupp, F. A. Ruhl, J. M. Pearce, D. M. Mulcahy, and M. A. Tomeo, "Effects of implanted radio transmitters with percutaneous antennas on the behavior of Canada Geese," Journal of Field Ornithology, vol. 74, no. 3, pp. 250-256, 2003.

[16] J. W. Hupp, J. M. Pearce, D. M. Mulcahy, and D. A. Miller, "Effects of abdominally implanted radiotransmitters with percutaneous antennas on migration, reproduction, and survival of Canada geese," Journal of Wildlife Management, vol. 70, no. 3, pp. 812-822, 2006.

[17] C. J. Latty, T. E. Hollmén, M. R. Petersen, A. N. Powell, and R. D. Andrews, "Biochemical and clinical responses of common eiders to implanted satellite transmitters," in Proceedings of the 3rd North American Sea Duck Conference, p. 19, Québec City, Canada, November 2008, Poster 39.

[18] C. J. Latty, T. E. Hollmén, M. R. Petersen, A. N. Powell, and R. D. Andrews, "Dive performance of common eiders implanted with satellite transmitters," in Proceedings of the 3rd North American Sea Duck Conference, p. 13, Québec City, Canada, November 2008, Session 6.2.
[19] A. Mosbech, F. Merkel, D. Boertmann et al., "Thick-billed murre studies in Disko Bay (Ritenbenk), West Greenland, 2005-2006," NERI 749, p. 60, Aarhus University, 2009.

[20] G. H. Olsen and M. C. Perry, "Behavioral and physiological observations of white-winged scoters with surgically implanted transmitters," in Proceedings of the 3rd North American Sea Duck Conference, p. 17, Québec City, Canada, November 2008, Poster 14.

[21] G. H. Olsen and M. C. Perry, "Surgical implantation of satellite transmitters: techniques for improving results based on captive diving duck studies," in Proceedings of the 3rd North American Sea Duck Conference, p. 17, Québec City, Canada, November 2008, Poster 15. 

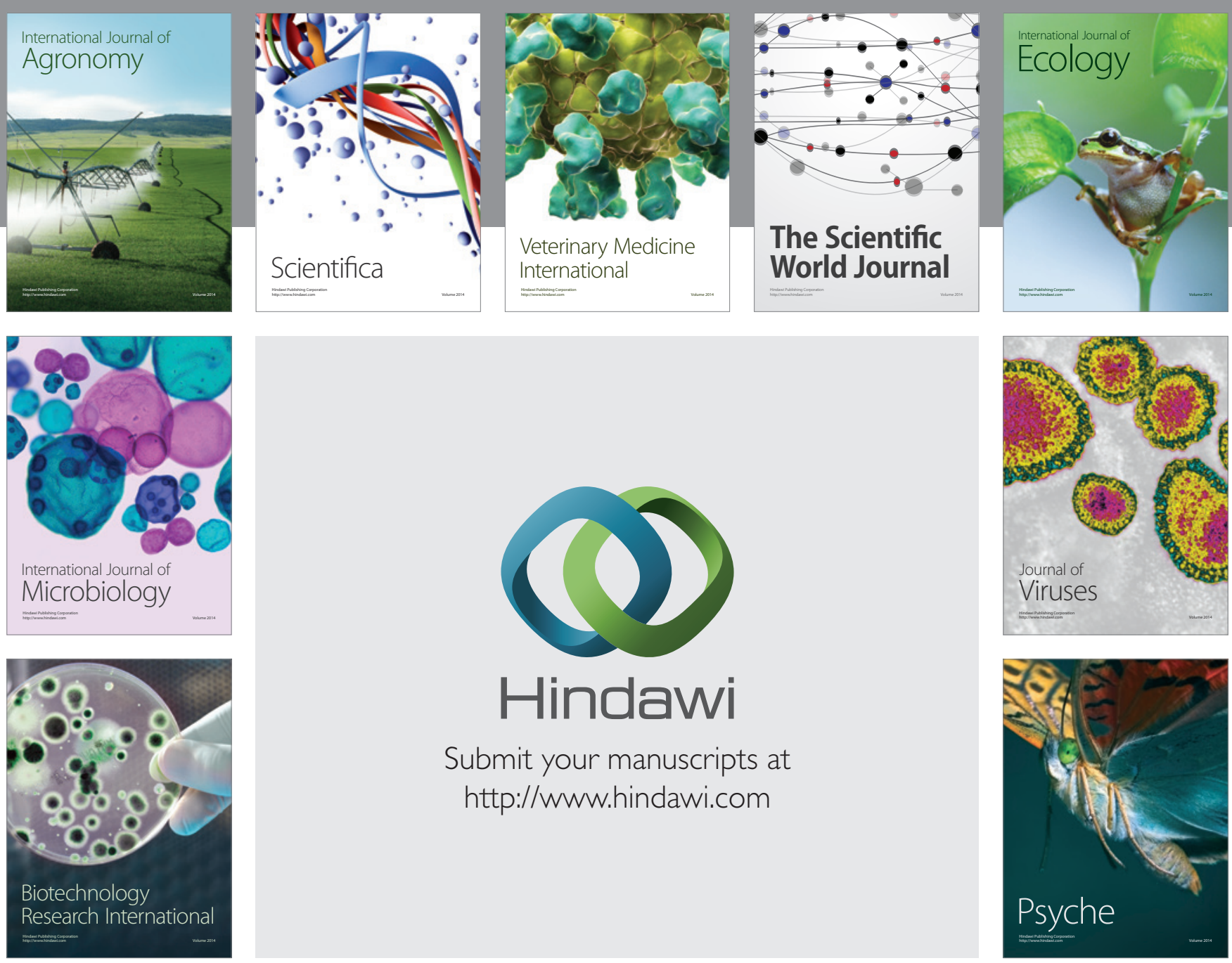

Submit your manuscripts at

http://www.hindawi.com
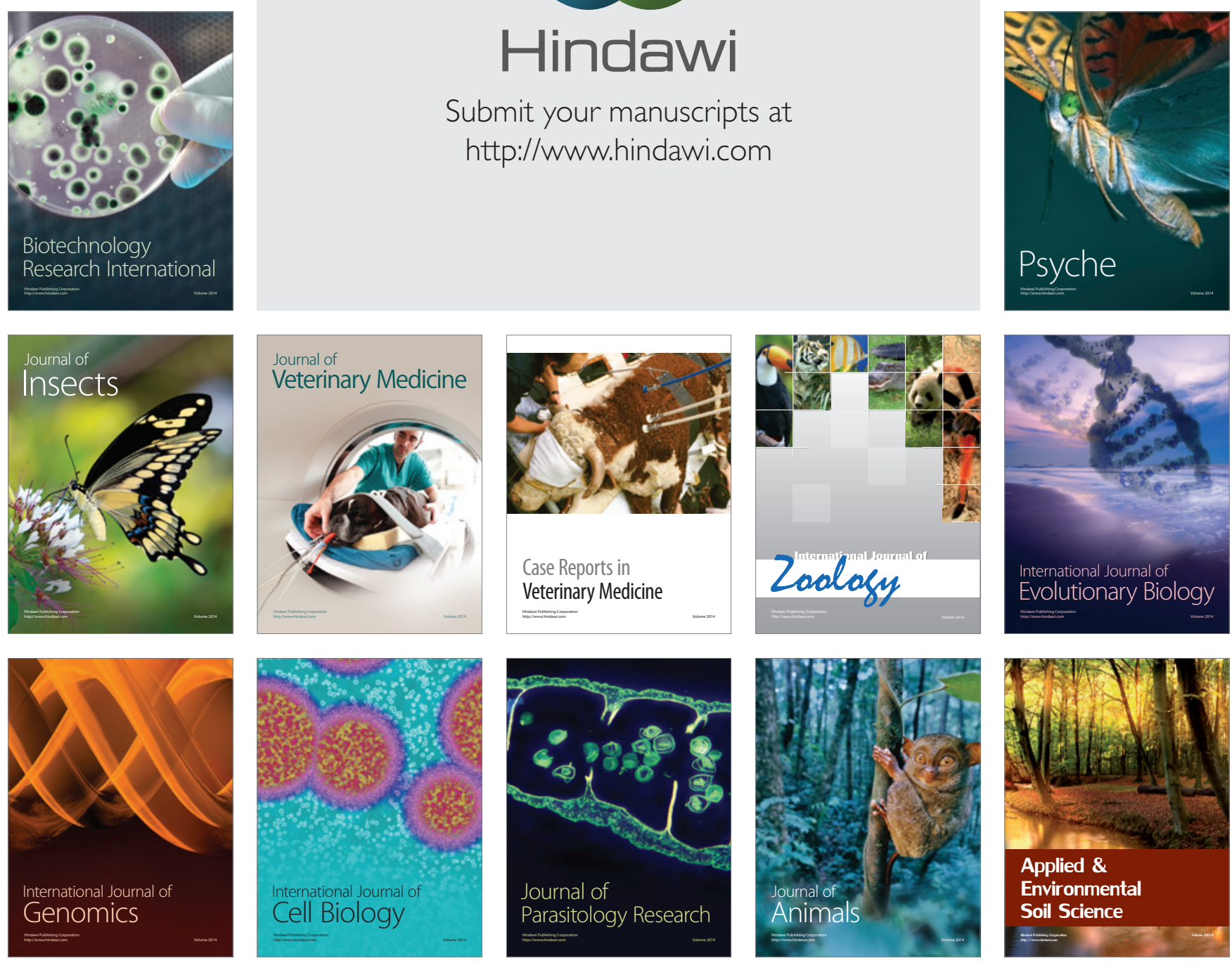